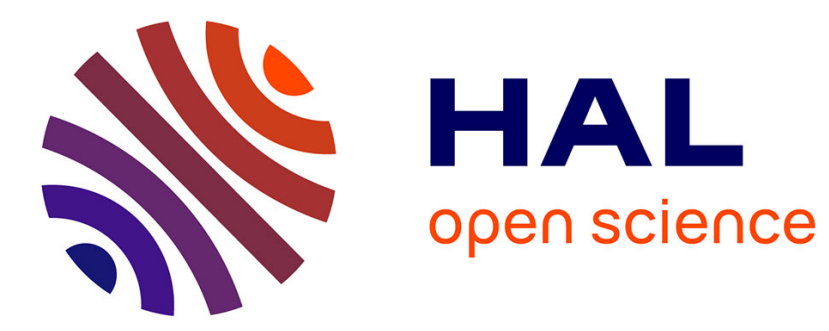

\title{
Binaural hearing and future hearing-aids technology
}

\author{
M. Bodden
}

\section{To cite this version:}

M. Bodden. Binaural hearing and future hearing-aids technology. Journal de Physique IV Proceedings, 1994, 04 (C5), pp.C5-411-C5-414. 10.1051/jp4:1994586 . jpa-00253081

\section{HAL Id: jpa-00253081 https://hal.science/jpa-00253081}

Submitted on 1 Jan 1994

HAL is a multi-disciplinary open access archive for the deposit and dissemination of scientific research documents, whether they are published or not. The documents may come from teaching and research institutions in France or abroad, or from public or private research centers.
L'archive ouverte pluridisciplinaire HAL, est destinée au dépôt et à la diffusion de documents scientifiques de niveau recherche, publiés ou non, émanant des établissements d'enseignement et de recherche français ou étrangers, des laboratoires publics ou privés. 


\title{
Binaural hearing and future hearing-aids technology
}

\author{
M. BODDEN
}

Lehrstuhl für allg. Elektrotechnik und Akustik, Ruhr-Universität Bochum, 44780 Bochum, Germany

\begin{abstract}
Normal-hearing persons can make use of two ears in daily listening, and this binaural hearing offers a lot of advantages compared to monaural hearing. The mechanisms of binaural hearing are based on an analysis of interaural differences and monaural cues that are due to directional dependent filtering of the outer ears as described by HeadTransfer Functions. In order to support the binaural abilities of hearing-impaired persons it is necessary to provide them with interaural and monaural cues that are in the range of their "natural" values. This can only be guaranteed if a new generation of hearing aids is introduced, namely binaural hearing aids, which consist of two hearing aids that are controlled by a central processor. This processor may have tasks ranging from an adjustment of the amplifications of both hearing aids up to a simulation of binaural processing which will support the understanding of speech in noise. A Cocktail-Party-Processor which may be used for this purpose and results of intelligibility tests are presented.
\end{abstract}

\section{BINAURAL HEARING}

Binaural hearing offers a lot of advantages in daily listening compared to monaural listening:

- sound sources can be localized in a three-dimensional space (spatial hearing)

- reverberation can be suppressed (precedence effect)

- interfering sound sources can be suppressed (Cocktail-Party-Effect)

Normal hearing persons are not always aware of these advantages, but hearing-impaired often have to resign them. Todays available hearing aids are able to enhance speech perception in quite and non-reverberant environments, but they are not able to support binaural abilities in an optimal manner or even to distinguish between desired and interfering signals. In order to achieve this it is first necessary to understand the processing underlying binaural hearing. This should help on one hand to improve fitting of todays available hearing-aids, but also to develop "intelligent" hearing aids which are able to simulate parts of binaural processing.

The abilities of binaural hearing are based on a kind of coder - decoder system. The coding is performed by the outer-ears as it can be described by means of the directional-dependent Head-Transfer Functions (HTF's). The decoding is performed on different higher levels of the auditory system, and the decodingmechanisms can be divided into three different categories: (a) the estimation of the azimuth, (b) frontback discrimination and elevation estimation, and (c) distance estimation. 
The estimation of the azimuth is based on an analysis of interaural differences in time (IDT) and intensity (IID). The interaural differences code the azimuth in a different manner: while IDT's are nearly independent on frequency and give unambiguous information about the azimuth, IID's highly depend on frequency, and in the mid-frequency range they become ambiguous for azimuth bigger than $60^{\circ}$. Even though they carry highly redundant information the auditory system does not evaluate them independently: the interaural differences form natural combinations which are characteristic for the azimuth, but also individual for each subject (Gaik, 1993). If a subject is confronted with a signal whose interaural differences do not fit the natural combinations, he may localize it inside of the head, or he may even perceive two different hearing events.

Front-back discrimination and elevation estimation can not be explained in detail yet. The historical interpretation is that monaural cues are evaluated (e.g., Blauert, 1983), but recent result suggest that binaural cues may play an important role, too (Hartung et al, 1993; Hartung, 1994). The monaural theory is based on investigations of Blauert, who found so-called directional bands. If third-octave bands of noise are presented to subjects in the median plane the perceived direction of incidence only depends on the frequency of the signal and not on the source position, e.g., $500 \mathrm{~Hz}$ is perceived in front, $1 \mathrm{kHz}$ in the rear, and $8 \mathrm{kHz}$ above the head. The interesting physical correlation is that the HTF's of the corresponding direction amplify the corresponding directional band. The dominant cues in daily listening are dynamic cues which are due to controlled movements of the head.

The estimation of the distance of a source uses spectral cues for distances less than three meters and mainly loudness information for distances up to 15 meters, which is the so-called acoustical horizon. If only acoustical information is available distances are usually underestimated.

The effects of spatial hearing on speech perception in noise can be quantified by means of the Binaural Intelligibility Difference (BILD), which states the difference of the level of an interfering signal in a comparison of monaural and binaural listening situations. In the binaural situation the level of the interfering signal can be up to $12 \mathrm{~dB}$ louder than in the monaural case to achieve the same intelligibility (Platte, 1979).

\section{CONSEQUENCES FOR HEARING AIDS CONCEPTS}

All the above mentioned mechanisms are combined in central stages of the auditory system to form hearing events with three-dimensional position information. Nearly all of the mechanisms are based on the evaluation of cues which are individual for each subject, and any kind of operation which changes the cues may result in reduced performance. The influence of the individual characteristics of the cues becomes obvious if dummy-head recordings are played back to subjects via earphones. Since the HTF's used during recording usually will differ from those of the listener in the playback situation, front-back reversals and localization inside of the head may occur. This means that the auditory system is very sensitive even to small changes in the localization cues, and that correct localization can only be guaranteed if the individual cues are present.

If a hearing-impaired person has to be supplied with a hearing aid, his binaural abilities can only be supported if both ears are supplied. Nevertheless conventional hearing aids may change the localization cues, most obviously for asymmetrical hearing losses and hearing aids with Automatic Gain Control (AGC). In this case the hearing aids may change the IID as a function of the absolute level of the signal, so that the combinations of interaural differences no longer fit the natural combinations the person is used to. In this case the auditory system may no longer be able to localize the source correctly, and the hearing event may even split up into two different events which are not outside, but inside of the head. A consequence will be that his binaural abilities, e.g., speech perception in noise, will be reduced.

This problem can be avoided if the two hearing aids do no. longer work independently, but are controlled by a central processor. One task of this processor will be to control the amplifications of the hearing aids 
in such a manner that the localization cues are in the range of the natural cues of the subject, so that his own remaining binaural abilities are optimally supported. But this concept of a binaural hearing aid can also support those hearing-impaired persons whose binaural abilities are reduced: the central processor can take over those parts of binaural processing which can no longer be performed by his own auditory system. The most important feature is a simulation of binaural selectivity, that is, a simulation of the Cocktail-Party-Effect which allows communication in noisy environments. The different strategies of hearing aids are summarized in Fig. 1. A system that is able to simulate the Cocktail-Party-Effect will be presented in the following chapter.

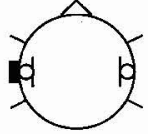

1. Monaural hearing aid

- localization hardly possible - poor speech intelligibility

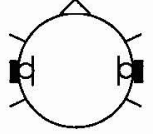

2. Two hearing aids

+ binaural abilities partly supported problems for asymmetrical hearing loss and $\mathrm{AGC}$

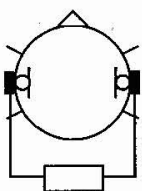

\section{Binaural hearing aid}

+ supports binaural abilities

+ central processor can simulate parts of binaural processing

Fig. 1: Hearing-aids concepts

\section{A COCKTAIL-PARTY-PROCESSOR}

The system developed at Bochum University is intended to model binaural hearing as far as it is known today. The concept as presented by Bodden $(1992,1993)$ is depicted in Fig. 2. The signals are recorded

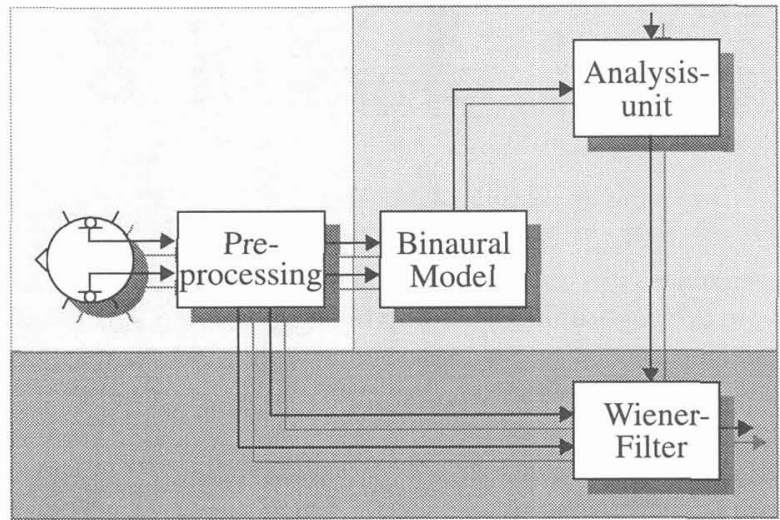

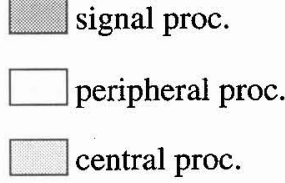

Fig. 2: Concept of the Cocktail-PartyProcessor

with a dummy head or miniature microphones in the earcanals, and the preprocessing comprises the peripheral stages of middle and inner ear, mainly represented by a bandpass-filterbank with 24 filters of the bandwidth of critical bands. The task of the binaural processor is to analyze the interaural differences in time and intensity. This processor which has been developed by Lindemann (1986) and Gaik (1993) is based on an interaural cross-correlation function that has been extended by a mechanism of contralateral inhibition, monaural processors and an adaptation to the individual characteristics of Head TransferFunctions. The output of the processor can be regarded as simulations of neural excitations. These patterns allow to simulate spatial selectivity of binaural hearing because the excitations due to sound sources of specific directions of incidence can be separated from excitations of sources form other directions. If the system knows the direction of incidence of the desired sound it can calculate the signal-to-noise ratio as a function of time and frequency, and using this information it can control a noise-cancelling algorithm which performs a time-varying weighting of the signal of each critical band filter. 
The performance of the algorithm has been tested in pilot experiments with hearing-impaired subjects where both, desired and interfering signals were speech signals. The first test has been designed as a word test consisting of 100 meaningless consonant-vowel-consonant (CVC) clusters that have been constructed from a statistic of the german language (Jekosch, 1990). The meaningless material ensures that the test reports the real percentage which the subjects comprehended, and excludes the influence of their deductive abilities. The words uttered by two different male speakers with similar voices have been recorded in an anechoic chamber and were binaurally mixed at a mean signal-to noise ratio of $0 \mathrm{~dB}$ so that one speaker was positioned to the left and the other to the right $\left(+/-30^{\circ}\right)$. These signals were dichotically presented to the subjects via earphones while they used their own hearing aids, whereas the processed signals have been presented diotically. The resulting comprehensibilities before and after processing of 5 hearing-impaired subjects is shown in Fig. 3. A significant enhancement of intelligibility can be stated, which also is valid for the consonant parts of the words. For the second test semantically unpredictable sentences have been used, and now a two-speaker-situation $\left(+/-30^{\circ}\right)$ and a three-speaker-situation $\left(-30^{\circ}, 0^{\circ},+30^{\circ}\right)$ has been investigated again at a mean signal-to-noise ratio of $0 \mathrm{~dB}$. The results for ten sentences and four subjects are shown in Fig. 4. For both situations the comprehensibilities are significantly enhanced.

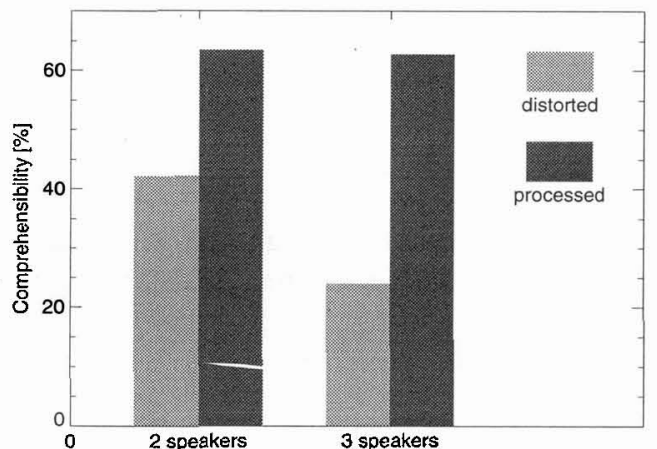

Fig. 3: Results of the sentence test

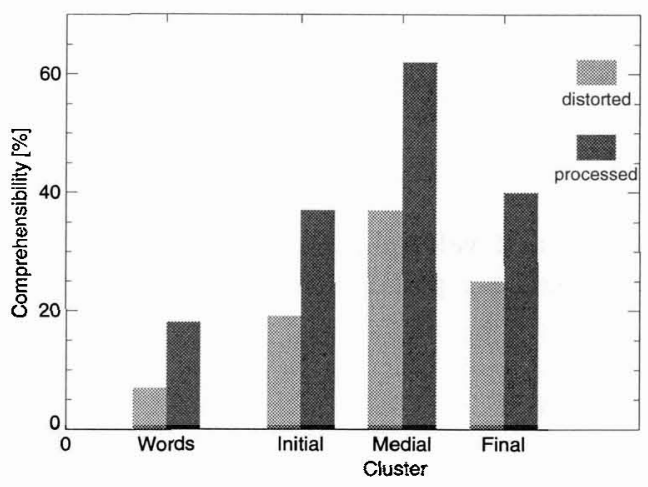

Fig. 4: Resuls of the word test

The results prove that the system is able to enhance speech intelligibility even if multiple concurrent speech signals are present. In order to implement this algorithm into future binaural hearing aids it will be necessary to simplify the processing and to develop special hardware so that it may run in realtime on a small device.

\section{4}

\section{LITERATURE}

BLAUERT, J. (1983): Spatial Hearing. MIT- Press, Cambridge, Mass.

BODDEN, M. (1992): Binaurale Signalverarbeitung: Modellierung der Richtungserkennung und des Cocktail-Party-Effektes. Fortschr.-Ber. VDI Reihe 17 Nr. 85. Düsseldorf: VDI-Verlag 1992.

BODDEN, M. (1993): Modeling Human Sound Source Localization and the Cocktail-Party-Effect. Acta Acustica $1(1), 43-55$.

GAIK, W. (1993): Combined Evaluation of Interaural Time and Intensity Differences: Psychoacoustic Results and Computer Modeling. J. Acoustical Society of America Vol. 94 No. 1, 98-110.

HARTUNG, K. (1994): Die Bedeutung der Kombination interauraler Zeit- und Pegeldifferenzen zur Vorne-HintenUnterscheidung bei Rauschen unterhalb von $2 \mathrm{kHz}$. Fortschritte der Akustik - DAGA ‘94, DPG- GmbH, Bad Honnef, in press.

HARTUNG, K; MIYOSHI, M; BODDEN, M; BLAUERT, J. (1993): Merkmale zur Vorne-Hinten- Unterscheidung unterhalb von $2 \mathrm{kHz}$. Fortschritte der Akustik - DAGA '93, DPG- GmbH, Bad Honnef, 836-839.

JEKOSCH, U. (1990): A weighted intelligibility measure for speech assessment. Proceedings of the 1990 Int. Conf. on Spoken Lang. Proc., Kobe, Japan, Nov. 1990, 973-976.

PLATTE (1979): Zur Bedeutung der Außenohreigenschaften für den Nachrichtenempfänger "menschliches Gehör". Dissertation, Aachen. 